\title{
Parametric Study of Offshore Pipeline Wall Thickness by DNV-OS-F101, 2010
}

\author{
Han-Suk Choi*, Su-Young Yu*, Dae-Hoon Kang** and Hyo-Dong Kang** \\ *Graduate School of Engineering Mastership, Postech, Pohang, Korea \\ *Daewoo Shipbuilding \& Marine Engineering Co., Seoul, Korea
}

KEY WORDS: Offshore pipeline wall thickness, Pressure containment, Collapse, Propagation buckling, Load controlled condition, Displacement controlled condition

\begin{abstract}
DNV-OS-F101 includes the concept development, design, construction, operation, and abandonment of offshore pipeline systems. The main objective of this offshore standard (OS) is to ensure that pipeline systems are safe during the installation and operational period. The pipeline design philosophy also includes public safety and environmental protection. The mechanical wall thickness design of a pipeline shall follow the design objectives and safety philosophy. This new design code includes a very sophisticated design procedure to ensure a safe pipeline, public safety, and environmental protection. This paper presents the results ofa parametric study for the wall thickness design of offshore pipelines. A design matrix was developed to cover the many design factors of pipeline integrity, public safety, and environmental protection. Sensitivity analyses of the various parameters were carried out to identify the impacts on offshore pipeline design.
\end{abstract}

\section{1. 서 론}

Det Norske Veritas (DNV) published the offshore pipeline design rules (DNV, 1976; DNV, 1981). These design rules were based on the working stress design and have been used over two decades. In the year 2000, DNV published first offshore standard (OS) DNV-OS-F101 for the design of the offshore pipeline systems with limit states or load and resistance factor design (LRFD). This offshore standard has been continuously updated based on various joint industry projects and many offshore installations (DNV, 2000, 2005, 2007, 2010). This new design code covers the all aspects of offshore pipeline system including concept development, design, construction, operation and abandonment at the end of production life. The main objective of this offshore standard is to ensure that pipeline systems are safe during the design life. Pipeline design philosophy also includes the public safety and environmental protection. Mechanical wall thickness design of a pipeline shall be followed by the design objectives and safety philosophy. This new design code includes a very sophisticated design procedure to ensure pipeline safety, public safety and environmental protection. Design and application to real projects were conducted by recent studies (Brown et al., 2004; Choi, 2006; Choi and Do, 2006; Choi et al., 2008; Choi et al., 2010).

This paper is presented to summarize the recent design code and to establish a wall thickness design matrix. The main objective of this paper is to assess a parametric study of the offshore pipeline design. A design matrix was developed to include many design factors of pipeline integrity, public safety, and environmental protection with a consistent design methodology. Parametric sensitivity analyses were carried out to identify the impacts on the offshore pipeline wall thickness design. Various results of the parametric study are presented.

\section{Safety, Concept Development and Design Premise}

An overall safety philosophy is applied in the concept development, design, construction, operation and abandonment of pipelines. DNV-OS-F101 defines two integrity stages: establishment of integrity in the concept development, design and construction phases; and maintaining integrity in the operating phases. The integrity of the offshore pipeline system is ensured through safety philosophy integrating with each of the different parts such as safety objective, systematic review, safety class methodology and quality assurance.

An overall safety objective shall be established, planned and implemented, covering all phases from a conceptual development to abandonment. Systematic review of risks shall be carried out at all phases to identify and evaluate threats, consequences of a single failure and series of failures in the pipeline system. A methodology for a systematic review is quantitative risk analysis (QRA). There are two 
parts of safety philosophy such as safety class methodology and quality assurance. Structural safety of the pipeline system is ensured by use of a safety class methodology based on failure consequences and a set of partial safety factors. Quality objectives are established by the operator of pipeline system and a quality assurance is controlled during all relevant phases.

Generally, pipeline system design is conducted in compliance with national legislation and company policy with respect to health, safety and environmental aspects as well as designated design codes such as DNV-OS-F101.

The objective of concept development and design premise provide a basis for the definition of relevant offshore field development characteristics. When selecting a pipeline system concept in a stage of development, all aspects related to design, construction, operation and abandonment shall be considered. Data and description of a field development and general arrangements of the pipeline systems are established.

The pipeline system shall be designed, constructed and operated in such a manner that the specified transport capacity is fulfilled and the flow assured. Resistance against loads and the safety margin against accidental loads or unplanned operational conditions shall be fulfilled. A design matrix was established to satisfy the concept development and design premise. Parameters which could affect on the integrity of a pipeline system were evaluated in this study.

\section{Design - Limit State Criteria}

All relevant limit states shall be considered in a design for all relevant phases and conditions. As a minimum requirement of an ultimate limit state, the offshore pipeline system shall be designed against bursting, ovalization/ratcheting, local buckling, global buckling, fatigue, unstable fracture and plastic collapse. The design matrix is based upon several limit states and partial safety factors, is also called as a load and resistance factor design.

The design load should be checked by the limit state design criteria. These criteria include load scenarios to be considered, categorization of loads such as functional, environmental and accidental loads. All loads and forced displacements which influence the pipeline integrity were considered in this study.

\subsection{Pressure containment (bursting)}

A bursting of pipeline due to the fluid pressure containment shall be satisfied the following criteria. The criteria are valid if the pipe mill pressure test has been satisfied. If not, a corresponding decreased utilization factor shall be applied. Reduction in pressure containment resistance due to true compressive forces (load controlled) shall be also considered.

$$
P_{l x}-P_{e} \leq \frac{P_{b}\left(t_{1}\right)}{\gamma_{m} \cdot \gamma_{S C}}
$$

where

$P_{l x}=P_{l i}$, local incidental pressure during operation

$P_{l x}=P_{l t}$, local system test pressure during system test

$P_{e}=$ external pressure

$\gamma_{m}=$ material resistance factor

$\gamma_{S C}=$ safety class resistance factor

$t_{1}=$ characteristic wall thickness

$P_{b}(t)=2 \cdot \frac{t}{(D-t)} \cdot f_{c b} \cdot \frac{2}{\sqrt{3}}$, pressure containment resistance

where

$t=$ pipeline wall thickness

$D=$ nominal outside diameter

$f_{c b}=\operatorname{Mnn}\left[f_{y} ; \frac{f_{u}}{1.15}\right]$

where

$f_{y}=$ yield stress

$f_{u}=$ tensile stress

3.2 Local buckling - external over-pressure only (system collapse)

The characteristic resistance for external pressure is calculated as:

$$
\begin{aligned}
& \left(P_{c}(t)-P_{e l}(t)\right) \cdot\left(P_{c}(t)^{2}-P_{p}(t)^{2}\right)=P_{c}(t) \cdot P_{e l}(t) \cdot P_{p}(t) \cdot \\
& f_{o} \cdot \frac{D}{t}
\end{aligned}
$$

where

$P_{c}(t)=$ characteristic resistance for external pressure (collapse)

$P_{e l}(t)=\frac{2 \cdot E \cdot\left(\frac{t}{D}\right)^{3}}{1-\nu^{2}}$, elastic collapse pressure

$P_{p}(t)=f_{y} \cdot \alpha_{f a b} \cdot \frac{2 \cdot t}{D}$, plastic collapse pressure

$f_{o}=\frac{D_{\max }-D_{\min }}{D}$, ovality

where

$\alpha_{f a b}=$ fabrication factor

$D_{\max }=$ greatest measured inside or outside diameter

$D_{\text {min }}=$ smallest measured inside or outside diameter

\subsection{Propagation buckling}

Propagation buckling cannot be initiated unless a local buckling has occurred. Propagation buckling results in very thick pipes. Propagation buckling is an option for the wall thickness design. If the external pressure exceeds the propa- 
gation criteria, buckle arrestors should be installed. A buckle arrestor capacity depends on propagating buckle resistance of adjacent pipes and size of the buckle arrestor (Torseletti et al, 2003). The propagating buckle criterion is as below:

$$
P_{e}<\frac{P_{p r}}{\gamma_{m} \cdot \gamma_{S C}}
$$

where

$P_{p r}=35 \cdot f_{y} \cdot \alpha_{f a b} \cdot\left(\frac{t_{2}}{D}\right)^{2.5} \quad$ for $\quad D / t_{2}<45, \quad$ propagating

pressure

where

$t_{2}=$ characteristic wall thickness

\subsection{Local buckling - combined loading criteria}

\subsubsection{Load controlled condition (LCC)}

Load controlled condition is that the structural response is primarily governed by the imposed load. This design criterion can always be applied in place of a displacement controlled condition (DCC) (DNV, 2010).

\section{(1) Internal over-pressure}

Pipe members subjected to bending moment, effective axial force and internal over-pressure are deigned to satisfy the following condition:

$$
\begin{aligned}
& {\left[\gamma_{m} \cdot \gamma_{S C} \cdot \frac{\left|M_{S d}\right|}{\alpha_{c} \cdot M_{p}\left(t_{2}\right)}+\left[\frac{\gamma_{m} \cdot \gamma_{S C} \cdot S_{S d}\left(P_{i}\right)}{\alpha_{c} \cdot S_{p}\left(t_{2}\right)}\right]^{2}\right]^{2}+} \\
& \left(\alpha_{p}+\frac{P_{i}-P_{e}}{\alpha_{c} \cdot P_{b}\left(t_{2}\right)}\right)^{2} \leq 1 \\
& D / t_{2} \leq 45, P_{i}>P_{e}
\end{aligned}
$$

where

$M_{S d}=$ design moment

$S_{S d}=$ design effective axial force

$P_{i}=$ internal pressure

$S_{p}(t)=f_{y} \cdot \pi \cdot(D-t)^{3} \cdot t$, plastic capacity of effective axial force

$M_{p}(t)=f_{y} \cdot(D-t)^{3} \cdot t$, plastic capacity of design moment $\alpha_{c}=(1-\beta)+\beta \cdot \frac{f_{u}}{f_{y}}$, flow stress parameter

$\alpha_{p}=\left\{\begin{array}{ll}1-\beta & \frac{P_{i}-P_{e}}{P_{b}}<\frac{2}{3} \\ 1-3 \beta\left(1-\frac{P_{i}-P_{e}}{P_{b}}\right) & \frac{P_{i}-P_{e}}{P_{b}} \geq \frac{2}{3}\end{array}\right.$, effect of $D / t_{2}$ ratio

$$
\beta=\left\{\begin{array}{llr}
0.5 & \text { for } & D / t_{2}<15 \\
\left(60-D / t_{2}\right) / 90 & \text { for } & 15 \leq D / t_{2} \leq 60 \\
0 & \text { for } & D / t^{2}>60
\end{array},\right. \text { factor used in }
$$

combined loading criteria

(2) External over-pressure

Pipe members subjected to bending moment, effective axial force and external over-pressure are deigned to satisfy the following condition:

$$
\begin{aligned}
& {\left[\gamma_{m} \cdot \gamma_{S C} \cdot \frac{\left|M_{S d}\right|}{\alpha_{c} \cdot M_{p}\left(t_{2}\right)}+\left[\frac{\gamma_{m} \cdot \gamma_{S C} \cdot S_{S d}}{\alpha_{c} \cdot S_{p}\left(t_{2}\right)}\right]^{2}\right]^{2}+\left(\gamma_{m} \cdot \gamma_{S C} \cdot\right.} \\
& \left.\frac{P_{e}-P_{\min }}{P_{c}\left(t_{2}\right)}\right)^{2} \leq 1 \\
& D / t_{2} \leq 45, P_{i}<P_{e}
\end{aligned}
$$

where

$P_{\min }=$ minimum internal pressure

\subsubsection{Displacement controlled condition}

Displacement controlled condition is that the structural response is primarily governed by imposed geometric displacements.

(1) Internal over-pressure

Pipe members subjected to longitudinal compressive strain (bending moment and axial force) and internal over-pressure are designed to satisfy the following condition:

$$
\epsilon_{S d} \leq \epsilon_{R d}=\frac{\epsilon_{c}\left(t_{2}, P_{\mathrm{min}}-P_{e}\right)}{\gamma_{\epsilon}} D / t_{2} \leq 45, \quad P_{i} \geq P_{e}
$$

where

$\epsilon_{S d}=$ design compressive strain

$\epsilon_{c}\left(t_{2}, P_{\min }-P_{e}\right)=0.78 \cdot\left(\frac{t}{D}-0.01\right) \cdot\left(1+5.75 \cdot \frac{P_{\min }-P_{e}}{P_{b}(t)}\right) \cdot$

$\left(\alpha_{h}\right)^{-1.5} \cdot \alpha_{g w}$

$\gamma_{\epsilon}=$ strain resistance factor

$\alpha_{g w}=$ girth weld factor

$\alpha_{h}=\left(\frac{R_{t 0,5}}{R_{m}}\right)_{\max }$, minimum strain hardening

where

$R_{t 0,5}=$ strength equivalent to a total elongation of $0.5 \%$ (actual stress)

$R_{m}=$ tensile strength

(2) External over-pressure

Pipe members subjected to longitudinal compressive strain and external over-pressure are designed to satisfy the following condition:

$$
\left(\frac{\epsilon_{S d}}{\epsilon\left(t_{2}, D\right) / \gamma_{\epsilon}}\right)^{0.8}+\frac{P_{e}-P_{\min }}{P_{c}\left(t_{2}\right) /\left(\gamma_{m} \cdot \gamma_{S C}\right)} \leq 1 \quad D / t_{2} \leq 45, \quad P_{\min }<P_{e}
$$

\section{Design Matrix}

\subsection{Input parameters}

Input parameters used in a benchmark case are shown in Table 1. These data were taken from the Sakhalin 1, Chayvo- 
Table 1 Input parameters for wall thickness calculation (Benchmark case)

\begin{tabular}{cc}
\hline \hline Input & Value \\
\hline Outside diameter & $914.4 \mathrm{~mm}$ \\
Corrosion allowance & $3 \mathrm{~mm}$ \\
Water depth & $21.8 \mathrm{~m}$ \\
Burial depth & $2.35 \mathrm{~m}$ \\
Design pressure & $9.763 \mathrm{MPa}$ \\
Operating temperature & $68^{\circ} \mathrm{C}$ \\
Effective axial force & $222.4 \mathrm{kN}$ \\
Moment & $1897 \mathrm{kN} \cdot \mathrm{m}$ \\
Strain & 0.002 \\
Specified minimum yield stress & $415 \mathrm{MPa}$ \\
Specified minimum tensile stress & $520 \mathrm{MPa}$ \\
Elastic modulus & $207 \mathrm{GPa}$ \\
Poisson ratio & 0.3 \\
\hline
\end{tabular}

Orlan pipeline project (Technip, 2005).

\subsection{Design matrix}

A design matrix was developed to include the design factors of pipeline integrity, public safety, and environmental protection in DNV-OS-F101. This design matrix was deve- loped under a consistent design methodology and philosophy for wall thickness design. Then, this design matrix was used for a benchmark case and a parametric study. The design matrix for the benchmark case of wall thickness is internal over-pressure problem as shown in Table 2. The benchmark case shows the negligible results for external over-pressure cases. External over-pressure and other parametric studies are presented in the following section.

\section{Parametric Sensitivity Analyses}

Parameters and the varied values used in sensitivity analyses are indicated in Table 3. After numerous calculations, appropriate ranges of variables were determined to identify their sensitivities.

Fig. 1 shows a parametric analysis of water depths for internal over-pressure cases. Propagation buckling is the most sensitive to the water depth. Displacement controlled combined load cases are also sensitive to water depth due to minimum internal pressure that can be continuously sustained with the associated strain. However, load controlled combined conditions indicate tendency of decrement of wall thickness due to maximum internal pressure. Water depth increments have also negative effects for pressure containment cases.

Table 2 Design matrix for wall thickness calculations (Benchmark case)

\begin{tabular}{|c|c|c|c|c|}
\hline Case & Description & System condition & Wall thickness (mm) & Code section \\
\hline \multirow{4}{*}{ Pressure containment (bursting) } & Operation & Low & 16.5 & \multirow{4}{*}{ D200 } \\
\hline & Operation & Medium & 17.6 & \\
\hline & Operation & High & 19.8 & \\
\hline & System test & Low & 14.5 & \\
\hline $\begin{array}{c}\text { Local buckling - External } \\
\text { over-pressure (system collapse) }\end{array}$ & Installation \& operation & High & 13.6 & D400 \\
\hline Propagation buckling & Installation \& operation & High & 19.4 & D500 \\
\hline \multirow{4}{*}{$\begin{array}{l}\text { Local buckling - Combined } \\
\text { loading criteria } \\
\text { (load controlled condition) }\end{array}$} & $\begin{array}{l}\text { Internal over-pressure } \\
\text { (System check) }\end{array}$ & \multirow{2}{*}{ High } & 14.3 & \multirow{2}{*}{ D605 } \\
\hline & $\begin{array}{l}\text { External over-pressure } \\
\text { (System check) }\end{array}$ & & 1.2 & \\
\hline & $\begin{array}{l}\text { Internal over-pressure } \\
\text { (Local check) }\end{array}$ & \multirow{2}{*}{ High } & 13.1 & \multirow{2}{*}{ D607 } \\
\hline & $\begin{array}{c}\text { External over-pressure } \\
\text { (Local check) }\end{array}$ & & 1.1 & \\
\hline \multirow{4}{*}{$\begin{array}{c}\text { Local buckling - Combined } \\
\text { loading criteria } \\
\text { (displacement controlled } \\
\text { condition) }\end{array}$} & $\begin{array}{l}\text { Internal over-pressure } \\
\quad \text { (System check) }\end{array}$ & \multirow{2}{*}{ High } & 19.8 & \multirow{2}{*}{ D608 } \\
\hline & $\begin{array}{l}\text { External over-pressure } \\
\text { (System check) }\end{array}$ & & 20.8 & \\
\hline & $\begin{array}{l}\text { Internal over-pressure } \\
\text { (Local check) }\end{array}$ & \multirow{2}{*}{ High } & 18.9 & \multirow{2}{*}{ D609 } \\
\hline & $\begin{array}{l}\text { External over-pressure } \\
\text { (Local check) }\end{array}$ & & 20.1 & \\
\hline
\end{tabular}


Table 3 Parameters for sensitivity analyses

\begin{tabular}{cc}
\hline \hline Parameters & Values \\
\hline Water depth & $0 \sim 950 \mathrm{~m}$ \\
(Internal over-pressure) & \\
Water depth & $100 \sim 1,000 \mathrm{~m}$ \\
(External over-pressure) & $0 \sim 5 \mathrm{~m}$ \\
Burial depth & $-5,000 \sim 5,000 \mathrm{kN}$ \\
Axial force & $-5,000 \sim 5,000 \mathrm{~N} \cdot \mathrm{m}$ \\
Moment & $0 \sim 0.01$ \\
Strain & $50 \sim 200{ }^{\circ} \mathrm{C}$ \\
Temperature &
\end{tabular}

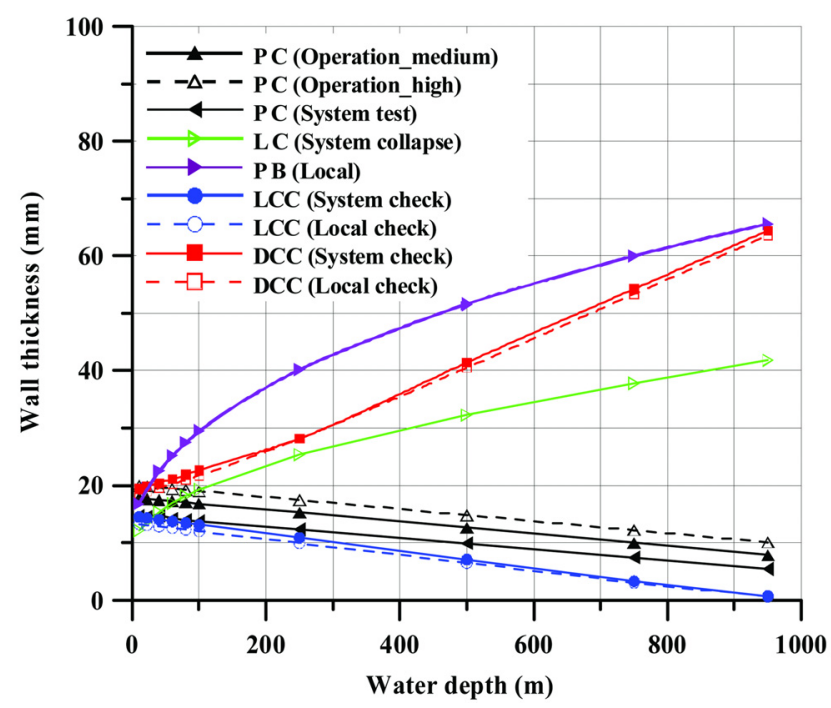

Fig. 1 Wall thickness results of water depths for internal overpressure cases $(\mathrm{Pi}=9763 \mathrm{kPa})$

Fig. 2 indicates a parametric analysis of water depths for external over-pressure cases. Propagation buckling is the most

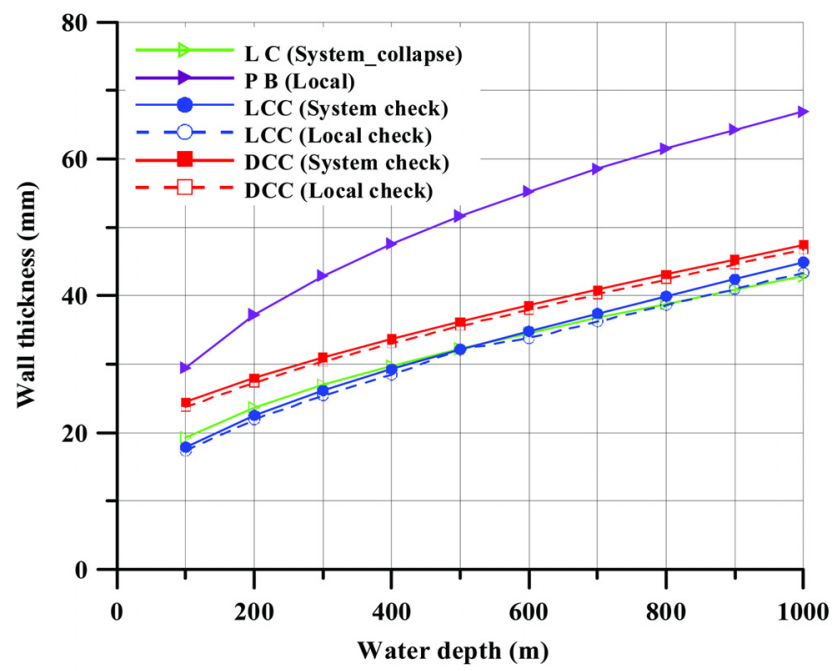

Fig. 2 Wall thickness results of water depths for external overpressure cases $(\mathrm{Pi}=976 \mathrm{kPa})$ sensitive to the wall thickness design. Both of the combined load cases are also sensitive to wall thickness. Results of pressure containment does not appear in this figure due to external over-pressure cases.

Fig. 3 illustrates a parametric analysis of pipeline burial depths. The results of parametric study are separated into two groups. Upper group including pressure containment in operation, propagation buckling and displacement controlled condition is more sensitive than lower group. Most of the results show mild rates of increments with respect to pipeline burial depths.

Fig. 4 shows a parametric analysis of effective axial forces. Effective axial forces have influence only on load controlled combined conditions. Wall Thickness is very sensitive to axial force increment. Increments of wall thicknesses by compressive and tensile force are symmetric.

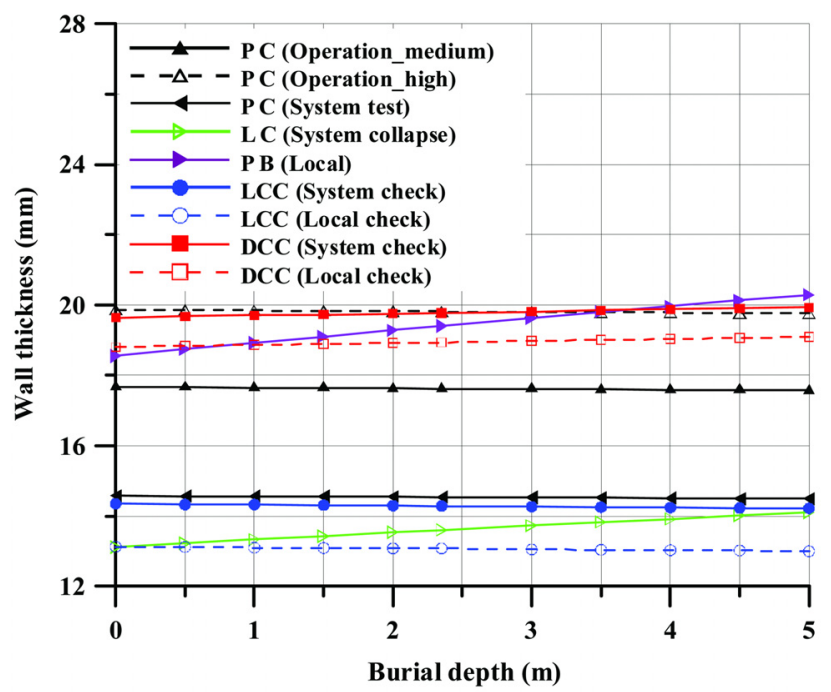

Fig. 3 Wall thickness results of burial depths

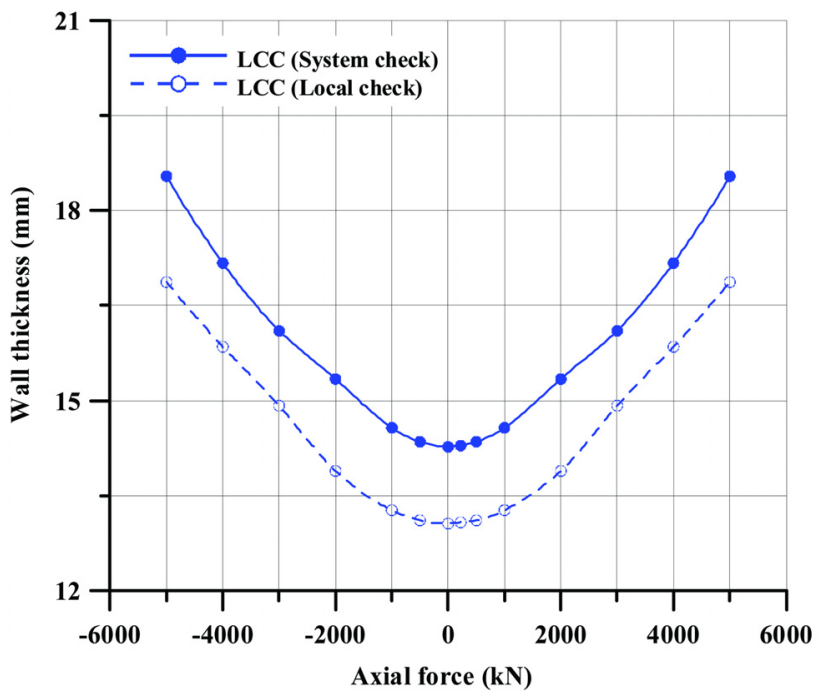

Fig. 4 Wall thickness results of effective axial forces 
Fig. 5 illustrates a parametric analysis of moments on pipeline systems. Moment has a significant influence only on load controlled combined conditions for wall thickness design. There are little differences in wall thicknesses between system check cases and local check cases due to the load control condition by external moments.

Fig. 6 shows a parametric analysis of strains due to pipeline installation. System check cases in displacement controlled condition are more sensitive than load controlled condition. As strains are increased, the wall thickness in system check case is increased linearly within allowable strain limits.

Fig. 7 shows a parametric analysis of operational temperatures. Pressure containment in the high safety case and operation case are the most sensitive to the operational temperatures. Displacement controlled condition and propagation buck

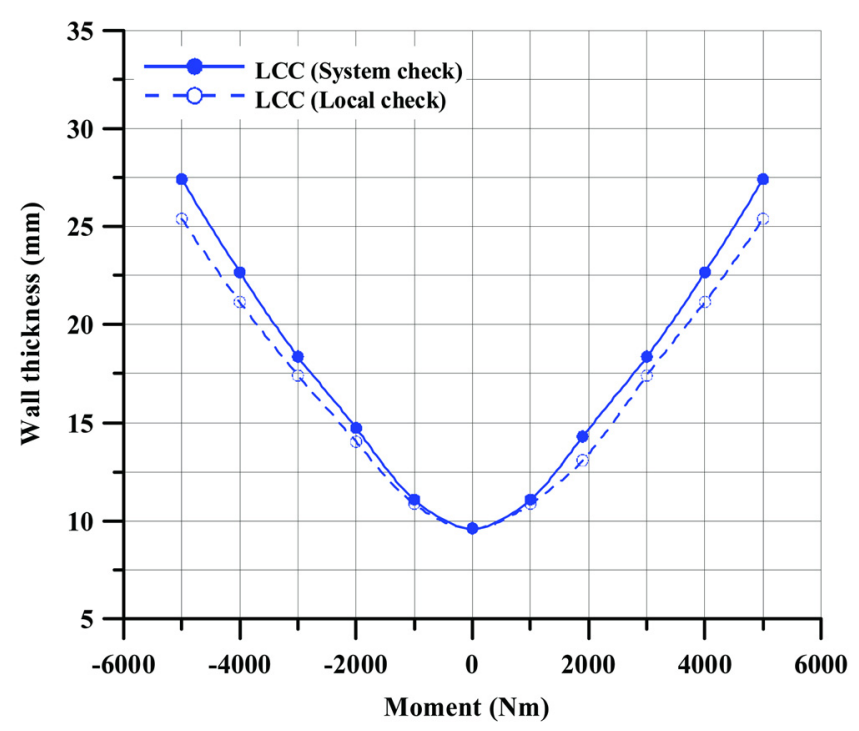

Fig. 5 Wall thickness results of external moments

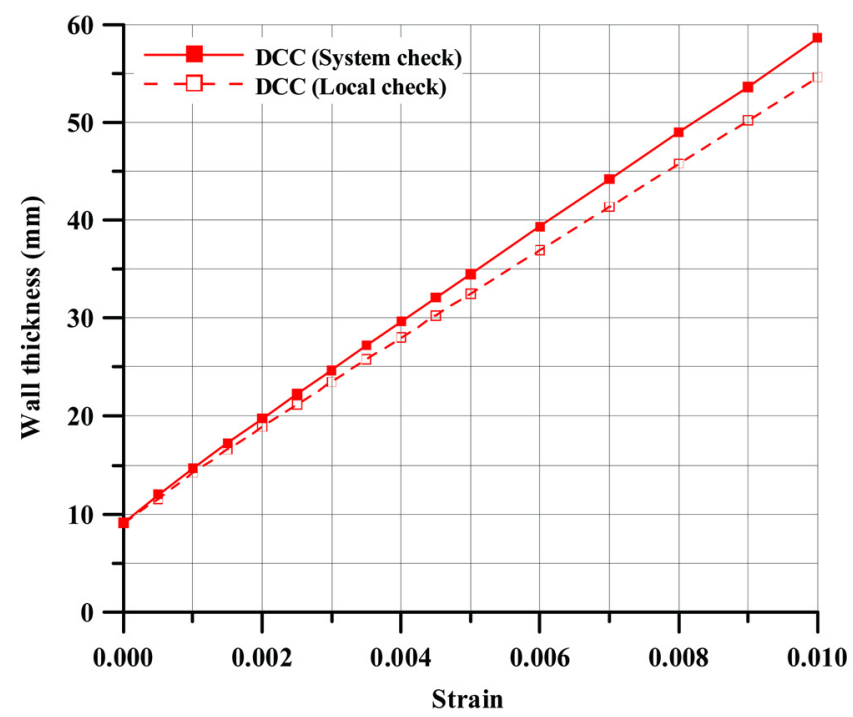

Fig. 6 Wall thickness results of pipeline strains

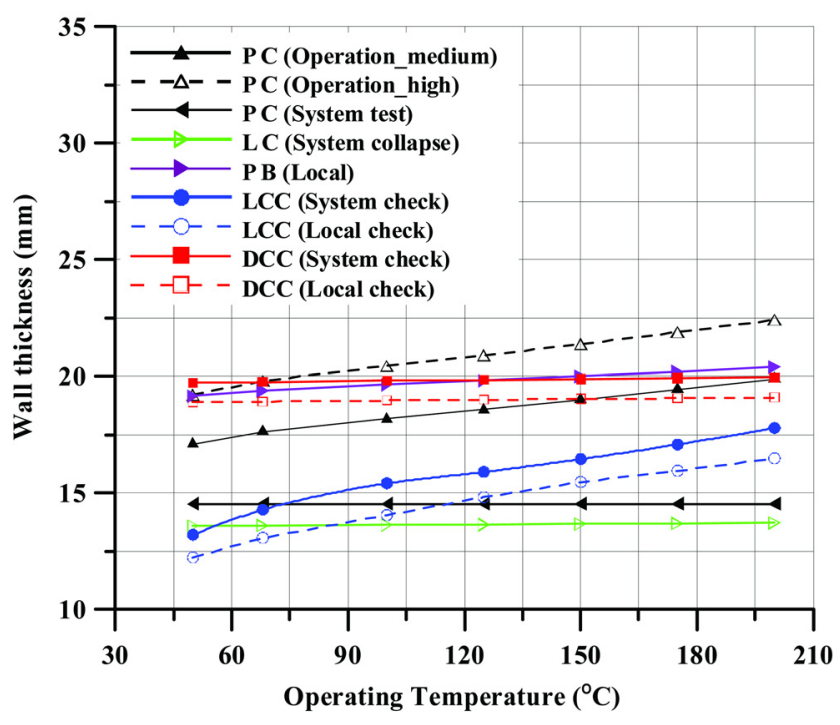

Fig. 7 Wall thickness results of operating temperatures

ling cases are also sensitive to the operational temperatures. But load controlled condition cases show mild increments of wall thicknesses.

Fig. 8 shows a summary of the parametric sensitivity analyses. Vertical axis indicates the ratios of wall thicknesses between the benchmark case and sensitivity analyses. Horizontal axis indicates the ratios of the parameters between the benchmark case and sensitivity analyses. Load controlled cases due to external moments and installation strains are most sensitive to wall thickness design. Water depth is also sensitive to wall thickness, but less sensitive than combined load cases. Remaining parameters such as burial depth, axial force, and operating temperature have little influences for wall thickness design. These tendency is similar to the results of Vitali et al (1999).

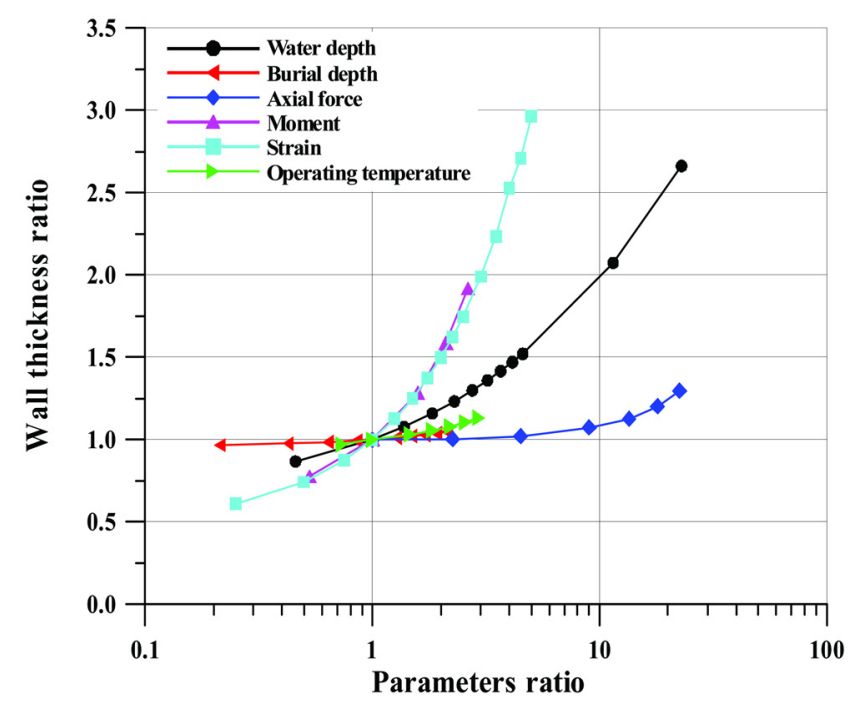

Fig. 8 A summary of the parametric sensitivity analyses 


\section{Concluding Remarks}

Following concluding remarks were obtained from the parametric sensitivity study.

(1) A design matrix was developed in accordance with DNVOS-F101, 2010. Then the design matrix was used for a real project benchmarking and parametric sensitivity analyses.

(2) In case of water depth variations, propagation buckling is the most sensitive to the wall thickness design.

(3) Results of pipeline burial depth variation are separated into two groups. The group including pressure containment in operation, propagation buckling and displacement controlled condition is sensitive to wall thickness design.

(4) Effective axial forces and moments have influenced only load controlled conditions. The results of system check cases are higher than those of local check cases.

(5) System check cases in displacement controlled conditions are more sensitive than those of load controlled conditions.

(6) Results of operational temperature variation show that pressure containment, displacement controlled condition and propagation buckling cases are sensitive to the wall thickness design.

(7) External moments and installation strains are the most sensitive to wall thickness design. Water depth is an important variable to design wall thickness, but less sensitive than the combined load cases.

$$
\text { 후 기 }
$$

본 연구는 대우조선해양(주)의 지원으로 수행된 연구결과 입니다.

\section{참 고 문 헌}

Brown, G., Tkaczyk, T. and Howard, B. (2004). “Reliability Based Assessment of Minimum Reelable Wall Thickness for Reeling", Proceeding of IPC 04-0733, IPC Calgary, Alberta, Canada.
Choi, H.S. (2006). "A Benchmark Study of Design Codes on Offshore Pipeline Collapse for Ultra-Deepwater", The Society of Naval Architects of Korea, SOTECH, Vol 10, No 1, pp 38-46.

Choi, H.S. and Do, C.H. (2006). "Integrated Expansion Analysis of Pipe-In-Pipe Systems", Journal of Ocean Engineering and Technology, The Korean Society of Ocean Engineers, Vol 20, No 5, pp 9-14.

Choi, H.S., Lee, S.K. and Chun, E.J. (2008). "A Review of Expansion Behavior of Marine Pipelines", Journal of Ocean Engineering and Technology, The Korean Society of Ocean Engineers, Vol 22, No 2, pp 13-19.

Choi, H.S., Do, C.H. and Na, Y.J. (2010). “Expansion Spool Design of an Offshore Pipeline by the Slope Deflection Method", Journal of Ocean Engineering and Technology, The Korean Society of Ocean Engineers, Vol 24, No 5, pp 1-7. DNV (1976). Rules for the Design, Construction and Inspection of Submarine Pipelines and Pipeline Risers, Det Norske Veritas., Hovik.

DNV (1981). Rules for the Submarine Pipeline Systems, Det Norske Veritas., Hovik.

DNV (2000, 2005, 2007, 2010). Submarine Pipeline Systems, Offshore Standard DNV-OD-F101, Det Norske Veritas., Hovik.

Technip (2005). Mechanical Design of Chayvo-Orlan Pipelines, NCS Sakhalin 1 EPC 2 - Offshore Pipeline, Doc. No. RUSA-RJE-GL-YR-61600.8115, Technip, Houston.

Torseletti, E., Bruschi, R., Marchesani, F. and Vitali, L. (2003). "Buckle Propagation and its Arrest: Buckle Arrestor Design Versus Numerical Analyses and Experiments", Vol 2, OMAE 2003-37220, pp 661-674.

Vitali, L., Bruschi, R., Mørk, K. and Verley, R. (1999). "Hotpipe project - Capacity of Pipes Subjected to Internal Pressure, Axial Force and Bending Moment", Proc. 9th Int. Offshore and Polar Engineering Conference, Brest.

2011년 8월 22일 원고 접수 2012년 1월 3일 심사 완료 2012년 4월 19일 게재 확정 